\title{
Friendly-Contention Ads Using Multiple Endorsers: Assessing Source Effects On Attribute Perceptions And Brand Attitudes
}

Kathy L. Pettit-O'Malley, (E-mail: komalley@uidaho.edu), University of Idaho Carl S. Bozman, (E-mail: bozman @jepson.gonzaga.edu), Gonzaga University

\begin{abstract}
Our study is a preliminary investigation of multiple-source friendly-contention ads in which various endorsers argue about the brand's main benefit(s). The results demonstrate that such an ad convinced viewers that originally seemingly inconsistent attributes and benefits could both be found in the advertised brand. Further, the tested advertising format produced more favorable brand attitudes than did an equivalently informative single-source ad version. The argumentative ad appears entirely appropriate in industries where a company wishes to target heavy product users.
\end{abstract}

\section{Introduction}

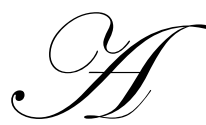

dvertisements that feature multiple spokespersons who argue a brand's benefits between or among themselves have become fairly common. Recall the long running Miller Lite campaign in which ex-athletes, referees, and celebrities argued as to whether the product was "Less Filling" or "Tastes

Great." During the course of this campaign, Miller Lite achieved the second largest market share in the United States and created a new light beer segment (Belch and Belch 1998).

Close on the heels of Miller Lite came ads for Polaroid featuring Mariette Hartley and James Garner, arguing the relative advantages of high picture quality versus the camera's ease of use. This earned the duo the Star Presenter Award for 1978, an award historically reserved for a single spokesperson. Another memorable ad campaign in this same genre was one for Folgers coffee. An attractive couple was shown enjoying a cup of coffee together. While he argued that the coffee was "rich," she favored its "mild" taste.

\section{Background}

A body of research exists which addresses why some multiple-source messages may be more effective than those with single sources, as well as factors that moderate their relative persuasiveness. The effect multiple spokespersons have on brand attitudes is determined by how consumers process the information presented in their arguments (Harkins and Petty 1981a, 1981b, 1983, and 1987).

Harkins and Petty (1981a) found that multiple-source multiple-argument messages resulted in more favorable cognitive responses and greater persuasion, than either: 1) single-source multiple-argument, or 2) multiple-source single-argument messages. Their three experiments showed that greater cognitive elaboration induced the greater persuasion of the multiple-source multiple-argument messages. Furthermore, the greater persuasional efficacy of the multiple-source multiple-argument ads dissipated under conditions of distraction

Readers with comments or questions are encouraged to contact the authors via email. 
(Harkins and Petty 1981b), indicating that when favorable elaborative thoughts are inhibited, such messages produce no more persuasion than more traditional messages.

The increased thinking by respondents exposed to the multiple-source multiple-argument messages resulted in greater persuasion when message arguments were strong, and lesser persuasion when the arguments were weak (Harkins and Petty 1981a). Specifically, increased persuasion followed increases in either favorable thoughts (e.g., source bolstering, pro-arguments, and favorable inferences) when the arguments used by the multiple sources were strong; decreases in persuasion followed increases in unfavorable thoughts (source derogation, counterarguments, and unfavorable inferences) when the arguments were weak.

A subsequent study by Moore and Reardon (1987) extended the research of Hawkins and Petty using advertising stimuli. Specifically, they found that when strong message arguments were employed, both positive thoughts and persuasion were higher using multiple sources rather than a single-source presentation. However, when weak message arguments were employed the results reversed. Under those conditions negative thoughts increased, and persuasion decreased, when one used a multiple-source presentation format rather than presentation by a single source. Their findings indicate that consumers are more diligent processing message claims for multiplesource arguments than single-source arguments.

Many studies have linked characteristics of an endorser to differential levels of persuasion. These investigations have focused primarily on spokesperson attractiveness, similarity of the spokesperson to the recipient, spokesperson expertise and spokesperson trustworthiness (cf. Wilson and Sherrell 1993). Spokespeople have been found to be most effective when they are viewed as relatively attractive, similar to the audience, perceived as trustworthy and as more expert.

A factor that often relates to perceived trustworthiness of a spokesperson relates to his/her reason(s) for the endorsement. Specifically, it may alter information processing if the message recipient believes the endorser is either paid or unpaid. Moore, Mowen and Reardon (1994) found that known remuneration or lack thereof for the message source(s) affected the relative efficacy of single- versus multiple-source messages. Specifically, results showed that message recipients exposed to multiple unpaid endorsers generated significantly more positive thoughts and attitudes than those exposed to a similar numbers of sources who were known to be paid endorsers. However, in single-source messages no differences in attitude favorability resulted from knowledge that the endorser was either paid or unpaid. Collectively, these studies indicate that consumers are more motivated to evaluate both message content and various peripheral issues related to multiple-source messages.

\section{Current Case}

Friendly-contention ads, differs from the messages reported above in several aspects. First, many of the previously-cited studies did not employ advertisements as messages. With two exceptions (Moore and Reardon 1987; Moore, Mowen and Reardon 1994), most single- versus multiple-source studies (Harkins and Petty 1981a, 1981b, and 1987) used persuasive messages that were counter-attitudinal, but unrelated to advertising.

Secondly, although differing arguments were given by various sources in previous studies, the arguments were not seemingly incompatible. For example, in one experiment (Harkins and Petty 1981a) student participants were exposed to messages advocating introduction of senior comprehensive exams at their university. Arguments in favor of their inclusion that were given by each of three fellow student sources were: 1) improved educational quality, 2) enhanced prestige of the university, and 3) higher-paying jobs for graduates. Although these arguments differ, they are totally compatible. However, in friendly-contention ads, the focal attributes argued over are at least somewhat at odds. For instance, in Miller's case a beer drinker might expect that a beer that "tastes great" would be more filling -- NOT less -- prior to viewing the ad. As a result, the ad contains both agreement in terms of brand choice between/among the various sources, and disagreement in terms of the brand's most appealing feature. This introduces a new type of discrepancy from that previously researched. It involves discrepancy both within the ad itself, as well as potential discrepancy between the sources and the viewers. 
Previous discrepancy research has examined the degree of disparity between the initial attitudes or opinions of the message recipient and those presented within the message. Such discrepancy would include both degree of difference in arguments between the ad source(s) and the message recipient, as well as the explicitly stated or implied recommendation. Under those conditions the optimal level of discrepancy has generally been described as moderate (cf., Sternthal, Phillips and Dholakia 1978). Specifically, too little discrepancy results in audience inattention; too much discrepancy results in stimulation of unfavorable thoughts by the message recipient. Source credibility has been found to moderate the discrepancy-persuasion relationship, such that with higher levels of credibility optimal levels of discrepancy are increased (cf. Brewer and Crano 1968; Koslin, Stoops and Loh 1967). Apparently, when the source(s) is perceived as more credible one will give his/her arguments more careful consideration. However, the type of discrepancy in the internally argumentative, friendly-contention ads has not been researched and reported.

The purpose of this article is to empirically assess the potential effectiveness of multiple-source advertisements that argue the brand's main benefit. Specifically, can a multiple-source ad, where at least two spokespeople present competing product benefits, produce superior effects compared to an ad employing a single spokesperson who makes identical claims? A series of hypotheses, derived from previous multiple-source findings, are presented and will be tested empirically. Results will be presented of this preliminary empirical investigation of the effects of friendly-contention ads. Finally, conclusions and managerial marketing implications of the results will be discussed, and limitations of the current study will be presented as suggestions for future research.

\section{Hypotheses}

Previous research indicates that the perception of endorser payment is one factor that can moderate the persuasiveness of advertisements. If a message recipient believes that the compensation the spokesperson receives is the primary motivator for the product's endorsement, his/her cognitive defenses are alerted. The result is that cognitive elaboration, if present, tends to become dominantly negative. It has been determined that when multiple sources are used to present information, respondents try to diligently evaluate the message. As a consequence, multiple-source advertisements would be most advisable in circumstances where an audience is likely to perceive that endorsers are sincere in their testimonials and/or receive no financial compensation.

How can we reconcile the widespread use of multiple-source ads with this result? Most people certainly view endorsements by celebrities and others as commercial activities (King 1989). We propose that an attitude accessibility explanation is useful for reconciling these seemingly incongruous outcomes. Previous studies have shown that attitude accessibility affects the nature of persuasive message elaboration and subsequent attitude formation (cf., Fabrigar et al. 1998; Petty, Unnava and Strathman 1991). Attitude accessibility reflects the strength of associations in memory, as well as the overall evaluation of an object (Berger and Mitchell 1989; Fazio, Powell and Williams 1989). An attitude is more accessible as emotional valance increases and/or if associations in memory for an object are extensive. Attitudes will guide the perception of a persuasive message to the extent that they are automatically activated and available. Attitudes high in accessibility have been shown to be more predictive of information processing behavior than attitudes low in accessibility (Hodges and Wilson 1993; Houston and Fazio 1989).

Message characteristics influence the ability and motivation to recall attitude-specific information (Schuette and Fazio 1995). The perception of endorser remuneration is just one of many plausible message characteristics that may influence the persuasiveness of multiple-source ads. Any differential evaluations evoked by an ad should influence persuasive impact. As others have found previously, we believe that a multiple-source ad will be more diligently processed than a single-source ad. Moore and Harkins (1987, p. 260) concluded that "multiple sources enhance message processing because of recipients' perceptions that information from multiple sources is more likely to be based on different perspectives and independent pools of knowledge and, thus, is more worthy of diligent consideration." Since previous research has shown that respondents process multiple-source arguments more diligently, and respond with more cognitive elaborations, it is predicted that the multiple-source ad will be superior at increasing the salience of any previously non-salient attributes presented focally in the ad. We hypothesize: 
H1: Focal brand attributes argued in a multiple-source friendly-contention ad will be salient following ad exposure, whether or not the attributes were salient prior to ad presentation. By contrast, previously nonsalient attributes presented by a similar single-source ad may not become salient following ad presentation.

Furthermore, the apparent independence of perspectives that is inherent in a friendly-contention multiplesource ad should buffer the effect of obvious spokesperson remuneration known to be part of advertising. Thus, the enhanced cognitive elaboration caused by the multiple sources is predicted to be favorable -- it will work in favor of accepting the claims made within the ad. Since the featured attributes appear to be incompatible prior to presentation of either ad, this greater claims acceptance should lead to a more positive perceived correlation of the focal attributes following exposure to the multiple-source ad only. As a consequence, an increase in perceived correlation (i.e., more positive) would essentially represent a reduction in a previous negative correlation between attributes.

H2: Perceived correlation between focally advertised attributes which initially appear at odds will become more positive following exposure to a multiple-source friendly-contention ad than following exposure to an equivalent content single-source ad.

Lastly, we speculate that friendly contention contained in a multiple-source ad, in contrast to a singlesource ad, will add to the perception that the spokespersons have both differing perspectives, and different experience-based knowledge. Thus, the effect of remuneration of the sources should be offset by their apparent independence. As such, greater elaboration caused by multiple sources is predicted to result in both more thoughts, and more favorable thoughts. The end result should be that attitudes are more favorable following exposure to friendly-contention ads because the viewer now believes that there are multiple good reasons to select the brand. Resultant brand attitude should be both more favorable, and more accessible. Hence:

H3: Brand attitudes will be more positive for multiple-source ads, where sources argue in favor of discrepant benefits, than for equivalent single-source ads.

\section{Methodology}

Forty-seven female college students who bake cakes at least once every-other month were asked to complete questionnaires concerning eight brands of cake mixes. Twenty-seven were assigned to an experimental group and twenty were assigned to a control group. Two weeks later, the control group was shown a cake mix ad that had been inserted in programming with other ads. The experimental group viewed the same programming with a multiple-source, friendly-contention ad substituted for the single source-ad. Identical cake mix questionnaires were administered to both groups immediately after viewing the in-class video, during a regular class session.

The programming was a segment of a TV talk show that had been taped off the air. Numerous ads, including either the single- or multiple-source cake mix ad, were interspersed throughout the video. The control condition advertisement showed a woman who had baked the company's brand of yellow cake. She claimed that it was both light and moist. The experimental group saw an ad that contained the same information as the control group. However, it contained multiple sources, presumably members of an extended family where two factions argued one or the other of the brand's benefits (moistness or lightness). The script of the multiple-source friendlycontention ad version is found in the Appendix.

The ad, for a Duncan Heinz Deluxe yellow cake mix, was provided by Compton Advertising, Inc. It had not aired in our area. According to the agency's spokesman, the ad's primary goal was to persuade consumers that their brand of cake mix had it all, while other brands had to settle for one benefit or another in their offerings. The ad was created after two major competitors had introduced a second line of cake mixes, both of which contained pudding in the mix. Both Pillsbury Plus and Betty Crocker Super Moist advertised their primary advantage as one of moistness. The competitors continued to supply many flavors of their original product line (i.e., without pudding), as well. 
The questionnaire first asked respondents to rate the similarity of twenty-eight pairs of various brands of cake mixes. The similarity questionnaire was collected, and a second part of the questionnaire was handed out. In it participants were asked questions about the importance of thirteen cake mix attributes (naturalness/no preservatives, cost, necessity of adding other ingredients, consistency of results, moistness, ease of preparation, purchase incentives, richness of flavor, preparation time, lightness of texture, color, freshness/shelf-life, and sweetness). They were also asked to rate each brand in terms of overall attitude and attribute perceptions. Included in the attribute perception assessment were questions related to moistness and light texture, the focal attributes presented in either $\mathrm{ad}$, as well as eleven presumably relevant, distractor attributes.

The last series of questions asked respondents to rate the likelihood that certain pairs of cake mix attributes could/would occur together. Although only the moist-light perceived correlation was of current interest, other reasonable pairs (e.g., rich flavor-natural ingredients -- presumed positively correlated; low cost-consistent results -presumed negatively correlated) were also measured as distractor tasks. All measurements were based on 9-point semantic differential scales.

\section{Results}

We speculated that prior to ad presentation consumers would perceive the two benefits, moistness and lightness, to be logically inconsistent (i.e., mutually exclusive). Adding moistness to a cake would tend to give it a heavier texture. As a consequence, we anticipated that these attributes would be negatively correlated prior to viewing the multiple-source ad. If the ad had the intended effect, however, the perceived correlation between product characteristics should become more positive. Both attributes would also be salient following the presentation of a multiple-source advertisement. This should be true whether or not both attributes were salient prior to viewing the ad. Finally, we believed brand attitudes would be superior among consumers exposed to a multiple-source ad versus an equivalent single-source ad.

A 2 X 2 ANOVA was employed to determine the differential effects of the two ad formats on perceived correlation of the moistness and lightness attributes. The first factor was the TIME dimension, with measurements taken before and after ad exposure. The second factor was the AD FORMAT: single- versus multiple-spokesperson (friendly contention). The interactive effect of TIME X AD FORMAT was highly significant $(\mathrm{F} 1,90=8.62, \mathrm{p}<$ .01). A Duncan's Multiple Range Test comparing all four measurements revealed that three conditions (both groups prior to ad exposure and the post-exposure single-spokesperson group) did not differ significantly from each other. However, the perceived correlation between moistness and lightness was significantly more positive $(\mathrm{p}<.05)$ for the fourth group -- post-exposure to the multiple-source friendly-contention ad -- than in any of the other three conditions. This result was as predicted by $\mathrm{H} 2$. Table 1 contains a table of cell means.

The cell means have been graphed in Figure 1A, which reveal the interactive effect. Respondents were significantly more likely to believe a cake mix could be both moist and light following the multiple-source friendlycontention ad than either before ad viewing or after viewing of the equivalent single-source ad.

Asking respondents directly about perceived attribute correlations could be an obtrusive task and, as such, might reasonably be subject to demand characteristics. Specifically, some respondents might deduce what the researchers hoped to demonstrate regarding such perceived correlations, particularly after seeing the argumentative ad. To minimize the likelihood of biasing the results a between-subject design was employed: respondents viewed only one ad version or the other. Also, the original questionnaires were administered two full weeks prior to ad exposure and subsequent measurement and, when originally administrated, their stated purpose was to familiarize students with the technique of perceptual mapping which would be discussed later in the course. Additionally, the perceived correlation measures were placed at the very end of a fairly lengthy questionnaire. It is unlikely that a respondent would go back to the start and revise her earlier answers. Furthermore, the similarity ratings, at the very beginning of the questionnaire, had been collected previously and could not be altered. 
Table 1

Perceived Attribute Correlations and Brand Attitude Cell Means

\begin{tabular}{|c|c|c|}
\hline & Dependent & Measures \\
\hline Condition & Perceived Correlation $_{\text {(Moist, Light) }}$ & Brand Attitude \\
\hline Before Single-Source Ad & $2.3^{\mathrm{a}}$ & $4.1^{\mathrm{c}}$ \\
\hline After Single-Source Ad & $2.0^{\mathrm{a}}$ & $4.2^{\mathrm{c}}$ \\
\hline $\begin{array}{l}\text { Before Multiple-Source } \\
\text { Friendly-Contention Ad }\end{array}$ & $2.5^{\mathrm{a}}$ & $3.9^{\mathrm{c}}$ \\
\hline $\begin{array}{l}\text { After Multiple-Source } \\
\text { Friendly-Contention Ad }\end{array}$ & $4.2^{\mathrm{b}}$ & $6.3^{\mathrm{d}}$ \\
\hline
\end{tabular}

Note: Means within a column not sharing a superscript are significantly different by Duncan's Multiple Range Test at: 1 ) a,b -- $\mathrm{p}$ $<.05$, and 2) c,d -- p <.01. All measures are based on 9-point semantic differential scales, with higher numbers indicating more positive (less negative) perceived correlation and more favorable attitude.

Figure 1:

Effects of Time and Ad Format on the Perceived

Correlation of Moistness and Lightness

$\mathrm{R}_{\text {perceived }}$ Moist, Light

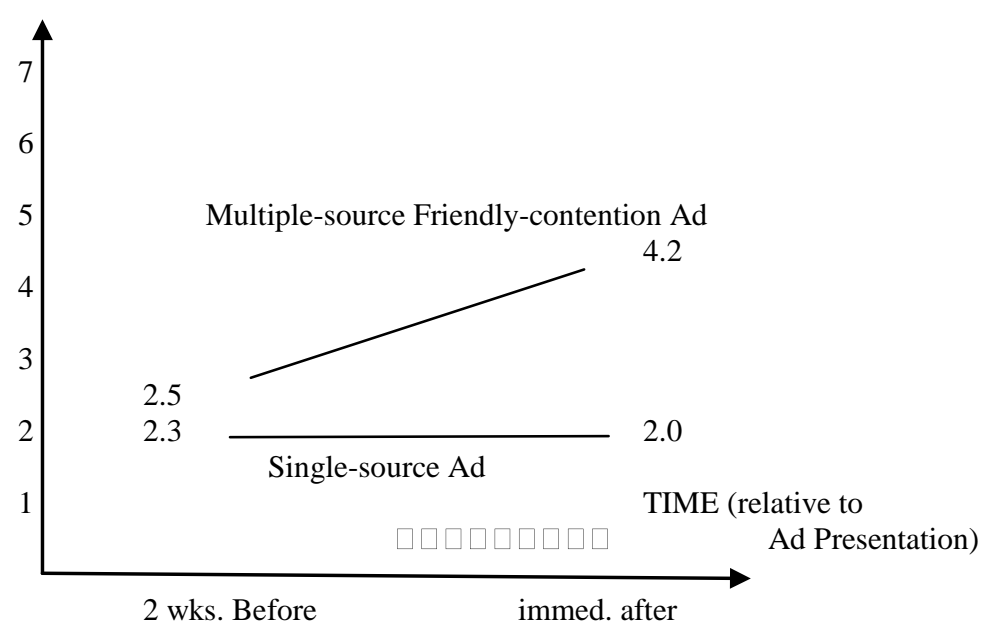

Thus, as a further test of changes in perceived attribute correlations, Multidimensional Scaling was employed on data from the beginning of the questionnaire. The ratings of similarity between brands of cake mixes which were collected prior to ad exposure were entered into a TORSCA algorithm, which produced the productperceptual space presented in Figure 2A. PROFIT (property-fitting-algorithm) and PREFMAP were then applied to plot in attribute vectors and an ideal point within the space for the respondents. As can be seen from Figure 2A, the 
horizontal axis relates largely to perceived moistness of various brands, whereas the vertical axis relates to perceived costliness of each. Note that the lightness vector was not proximal to either axis, indicating the attribute was not salient at the time respondents rendered their initial brand-similarity judgements. If lightness information was present in memory, it was not easily accessed at that time. The location of the ad-sponsoring brand and its two major competitors' new brands can be seen from the figure, as well as the ideal point. That point represents the most favored combination of attributes to the respondents.

The perceptual map shown in Figure 2A was derived from the experimental group two weeks prior to ad exposure. The moistness and costliness dimensions also dominated the control group's results both prior to and following viewing of the single-source ad. Furthermore, lightness was nonsalient in both the pre- and post-viewing control condition perceptual maps.

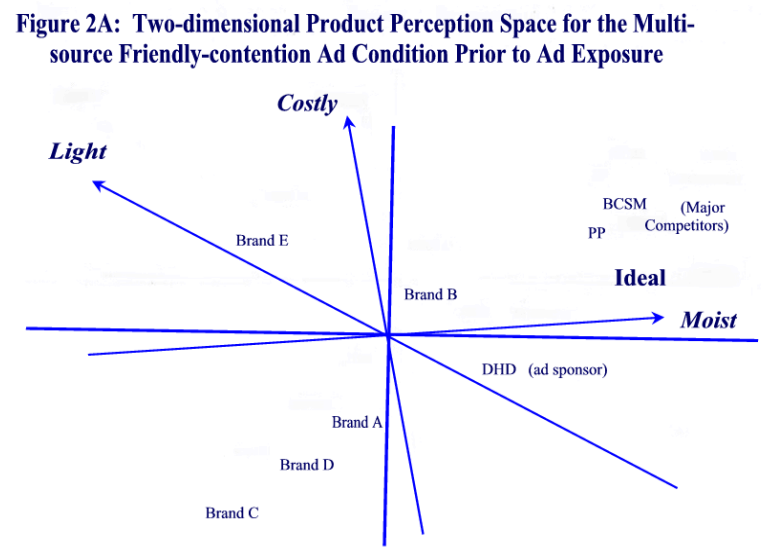

Figure 2B: Two-dimensional Product Perception Space for the Multisource Friendly-contention Ad Condition After Ad Exposure

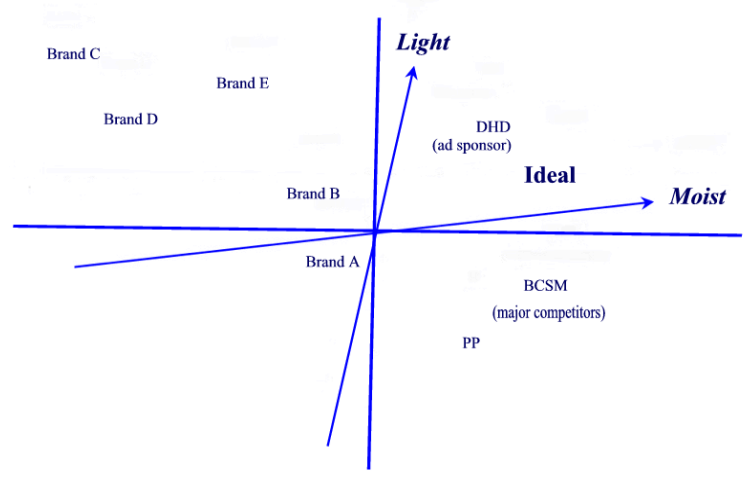

Note: $\mathrm{DHD}=$ Duncan Heinz Deluxe, ad sponsor. PP = Pillsbury Plus, $\mathrm{BCSM}=$ Betty Crocker Super Moist, both brands major competitor "pudding-in-mix" versions.
By contrast, the perceptual map in Figure 2B differs in three important aspects. In the second map, which was taken from the data that were obtained after exposure to the multiple-source friendly-contention ad, the axes are most clearly associated with the perceptual characteristics of moistness and lightness. Following exposure to the friendly-contention ad the previously nonsalient lightness attribute became highly salient. Lightness information became more accessible in memory and was employed when making comparative judgements of cake mix brands. This result is as predicted by $\mathrm{H} 1$.

Secondly, the moistness and lightness vectors are closer together in Figure 2B. The tips of the vectors have rotated toward each other, indicating that they have become perceptually more positively (less negatively) correlated. This result, which parallels that obtained by the more obtrusive perceived correlation measure, also supports H2. Lastly, the ad-sponsoring brand (Duncan Heinz), as seen in Figure 2B, is located closer to the ideal point in this map than in the previous one. Thus, one can infer that attitudes toward the ad-sponsoring brand have become more favorable following exposure to the multiplesource friendly-contention ad. This movement toward the ideal point is as predicted by $\mathrm{H} 3$. 
Further support for $\mathrm{H} 3$ was found when a 2 X 2 ANOVA was conducted on attitude measurements regarding the ad-sponsoring brand. Again, as in the first ANOVA, the two factors represented TIME (before and after ad exposure) and AD FORMAT (single- versus multiple-source friendly-contention ad). Cell means are listed in Table 1. Neither main effect was significant. However, the interactive effect of TIME X AD FORMAT was again significant $(\mathrm{F} 1,90=12.4, \mathrm{p}<.01)$, as shown in Figure 3. Brand attitudes for the sponsored product became more favorable over time for subjects in the multiple-source treatment, whereas no such favorable shift in brand attitudes followed exposure to the single-source condition. This result is also found in Table 1, and confirms H3. There were no significant shifts in brand attitudes for the two major competitors' brands following either ad presentation.

Figure 3:

Effects of Time and Ad Format

on Brand Attitude Favorability

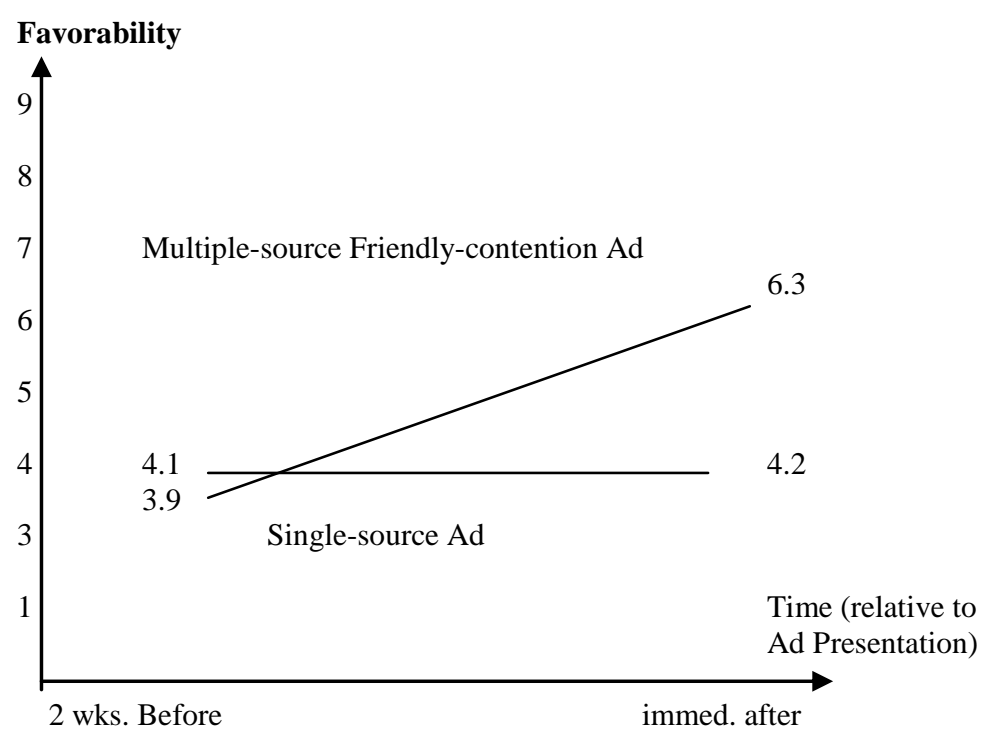

\section{Conclusions}

In the current study two versions of an equivalent content ad were presented, and resultant attribute perceptions and brand attitudes were assessed. In the multiple-source friendly-contention version various members of an "extended family" argued as to whether the brand's most important feature was moistness, or the cake's light texture. The alternative version presented a single source who argued with herself about the moist and light attributes (see Appendix). Our results show that a previously non-salient attribute, lightness, was made salient by the multiple-source version. No such effect was obtained following the single-source ad. Additionally, the two attributes (moist and light), which seemed to be inconsistent prior to ad exposure, became more positively correlated following the multiple-source ad version only. Finally, brand attitude in the multiple-source version improved following ad exposure. No such brand attitude improvement followed exposure to the more traditional ad format.

\section{Suggestions for Future Research}

Previous researchers who have examined the effects of using single versus multiple sources of message arguments (Harkins and Petty 1981a, 1981b, 1983 and 1987; Moore and Reardon 1987; Moore, Mowen and Reardon 1994) have concentrated on determining what causes either greater or lesser persuasion from either format. One initially plausible explanation was that when a message recipient observes more than one individual endorsing a 
position or product, he/she infers that the percentage of people, in general, who share the opinion is relatively greater than when he/she hears the opinion expressed by a single source. Through numerous previous experiments this hypothesis was eliminated. Rather, what they concluded caused differences in persuasion was that respondents cognitively process multiple-source messages more diligently. In many cases, due to this greater cognitive processing, the multiple-source message format was found to be more persuasive. For example, it was found to be particularly advantageous when the message arguments were strong, and when the sources were known to be either unpaid for their endorsements, or basing their opinion on independent perspectives. Conversely, when message arguments were weak and/or the sources were known to either be paid or appeared to be multiple mouths of identical opinions, the multiple-source messages generated more negative thoughts by respondents and lesser persuasion than did single-source messages.

In our study the intent was to study the effects of a particular type of advertisement which has received acclaim in the advertising industry. Such ads have multiple sources who, although they agree on brand choice, disagree on which attribute of the brand ensures their loyalty. Notably, the featured attributes always appear to be at odds. Great tasting beer should be filling (not less filling); rich coffee should be strong (not mild); moist cakes should be heavy (not light). These friendly contention ads, which clearly result in remuneration of spokespersons, seem to be effective.

In our case it was deemed critically important, at least in a preliminary investigation, to determine the effects of such ads regarding both attribute perceptions and brand attitudes. The questionnaires involved were lengthy, necessitated by the multi-dimensional scaling questions. The time required for participants to both view the video with inserted ads and to complete the lengthy questionnaire exhausted the scheduled class session. We did not believe we could lengthen the questionnaires or required tasks.

Our results are entirely consistent with the findings of others. It may well be that greater cognitive elaboration by the respondents exposed to the multiple-source version of the cake mix ad led to the observed shifts in attribute perceptions and brand attitude. However, numerous measurements omitted from the current study are worthy of inclusion in future research. For example, measurements of source credibility under both the single- and multiple-source versions would be desirable. It may be that because the sources appear to argue with each other within the ad, their commitment to their ideas appears to be more genuine. As such, the normal reduced credibility induced by their known remuneration may be offset by their apparent sincerity. Thus, their credibility (trustworthiness) may be enhanced. The old rule-of-thumb, that greater discrepancy from the original position of the audience is optimal when a highly credible source is used, may again be supported.

Furthermore, no thought-listing procedure was included in the current study. The effect of either ad version in terms of overall positive and negative thoughts warrants attention. Such thoughts could be recorded in future studies and categorized as not only favorable and unfavorable, but also as source-related, argument-related, and inferences made by the ad viewer. This could add further to our understanding of the effects of the friendlycontention ads.

It should also be noted that studies that examined the effects of various ad formats have found their effectiveness may be moderated by the sophistication of the target audience. Ad recipients who are more sophisticated -- i.e., more highly educated, more highly involved and/or familiar with the product -- may respond differently to various formats than do their less sophisticated counterparts. For instance, a more sophisticated audience tends to be more persuaded by an appeal which is: 1) two-sided -- i.e., one that presents both advantages and disadvantages of the advocated position (cf., Belch and Belch 1998; Smith and Hunt 1978), and 2) does not have the conclusion drawn for them (Sawyer and Howard 1991). However, for a less sophisticated audience the reverse type of appeals are more effective: 1) one-sided (advantages only) and 2) with the conclusion explicitly drawn. The moderating effect of sophistication seems to relate to cognitive elaboration differences between the two types of consumers. For example, source credibility of two-sided appeals has been found to be higher among educated consumers, who apparently infer that a source who discloses both advantages and disadvantages is more trustworthy and/or more knowledgeable (Faison 1961; Settle and Golden 1974). 
In the current study the respondent group was sophisticated. They were college-educated women who used the product frequently. Their reactions, as tested empirically and reported here, clearly favored choice of a multiplesource friendly-contention ad. However, would the effects have been the same with a more naïve audience? Many advertisers would not care. For instance, in the beer industry heavy users of the product category produce by far the majority of the sales. Thus, Miller probably made an extremely fortuitous choice of the friendly- contention format. Many frequent product users were persuaded by the claims, and switched to Lite. Our current results clearly suggest consideration of the ad format in consumer product categories in which a company wishes to segment on the basis of usage rate, and wants to target heavy product users.

Whether the ads are equally effective with a less sophisticated consumer group should be further investigated. Finally, even if differences in cognitive elaboration and attitudinal advantages are found for sophisticated audiences, and not for less familiar audiences, the effect of repetition needs to be investigated between ad formats. Perhaps single-source advertisements, when repeated frequently, are as persuasive as the friendlycontention ads favored in our results.

\section{References}

1 Belch, George E. and Michael A. Belch (1998), Advertising and Promotion: An Integrated Marketing Communications Perspective, Boston, MA: Irwin/McGraw-Hill.

2 Berger, Ida E. and Andrew A. Mitchell (1989), "The Effect of Advertising on Attitude Accessibility, Attitude Confidence, and the Attitude-Behavior Relationship," Journal of Consumer Research, 16 (December), 269-79.

3 Brewer, Marilyn B. and William D. Crano (1968), "Attitude Change as a Function of Discrepancy and Source of Influence," Journal of Social Psychology, 76, 13-18.

$4 \quad$ Fabrigar, Leandre R., Joseph R. Priester, Richard E. Petty, and Duane T. Wegener (1998), "The Impact of Attitude Accessibility on Elaboration of Persuasive Messages," Personality and Social Psychology Bulletin, 24(4), 339-352.

5 Faison, Edmund J. (1961), "Effectiveness of One-Sided and Two-Sided Mass Communications in Advertising," Public Opinion Quarterly, 25 (fall), 468-9.

6 Fazio, Russell H., Martha C. Powell, and Carol J. Williams (1989), "The Role of Attitude Accessibility in the Attitude-to-Behavior Process," Journal of Consumer Research, 16 (December), 280-288.

7 Harkins, Stephen G. and Richard E. Petty (1981a), "Effects of Source Magnification of Cognitive Effort on Attitudes: An Information-Processing View," Journal of Personality and Social Psychology, 40(3), 401413. and (1981b), "The Multiple Source Effect in Persuasion: The Effects of Distraction," Personality and Social Psychology Bulletin, 7(4), 627-635.

Sources and Multiple Targets," in Basic Group Processes, Paul Paulus, ed., NY: Springer-Vertag, 149-75.
and
(1987), "Information Utility and the Multiple Source Effect," Journal of Personality and Social Psychology, 52(2), 260-268.

11 Hodges, Sara D. and Timothy D. Wilson (1993), "Effects of Analyzing Reasons on Attitude Change: The Moderating Role of Attitude Accessibility," Social Cognition, 11(4), 353-366.

12 Houston, David A. and Russell H. Fazio (1989), "Biased Processing as a Function of Attitude Accessibility," Social Cognition, 7(1), 51-66.

13 King, Thomas R. (1989), "Credibility Gap: More Consumers Find Celebrity Ads Unpersuasive," The Wall Street Journal, (July 5): B5.

14 Koslin, Bertram L., James W. Stoops and Wallace D. Loh (1967), "Source Characteristics and Communication Discrepancy as Determinants of Attitude Change and Conformity," Journal of Experimental Social Psychology, 3, 230-42.

15 Moore, David J. and Richard Reardon (1987), "Source Magnification: The Role of Multiple Sources in the Processing of Advertising Appeals," Journal of Marketing Research, 24 (November), 412-417.

16 Moore, David J., John C. Mowen, and Richard Reardon (1994), "Multiple Sources in Advertising Appeals: When Product Endorsers Are Paid by the Advertising Sponsor," Journal of the Academy of Marketing 
Science, 22(3), 234-243.

17 Petty, Richard E., H. Rao Unnava, and Alan J. Strathman (1991), "Theories of Attitude Change," in Handbook of Consumer Behavior, T.S. Robertson and H.H. Kassarjian, eds. Englewood Cliffs, NJ: Prentice Hall.

18 Sawyer, Alan G. and Daniel J. Howard (1991), "Effects of Omitting Conclusions in Advertisements to Involved and Uninvolved Audiences," Journal of Marketing Research, 28 (Nov.), 467-74.

19 Schuette, Robert A. and Russell H. Fazio (1995), "Attitude Accessibility and Motivation as Determinants of Biased Processing: A Test of the MODE Model," Personality and Social Psychology Bulletin, 21(7), 704-711.

20 Settle, Robert E. and Linda L. Golden (1974), "Attribution Theory and Advertiser Credibility," Journal of Marketing Research, 11 (May), 181-185.

21 Smith, Robert E. and Shelby D. Hunt (1978), "Attributional Processes and Effects in Promotional Situations," Journal of Consumer Research, Vol. 5 (Dec.), 149-158.

22 Sternthal, Brian, Lynn W. Phillips, and Ruby Dholakia (1978), "The Persuasive Effect of Source Credibility: A Situational Analysis," Public Opinion Quarterly, 42:3 (Fall), 285-314.

23 Wilson, Elizabeth J. and Daniel L. Sherrell (1993), "Source Effects in Communication and Persuasion Research: A Meta_Analysis of Effect Size," Journal of the Academy of Marketing Science, 21(2), 101-112.

Appendix: Duncan Heinz Cake Mix Ad --

Multiple-Source Friendly-Contention Version

Scene: Picnic table with members of extended family on either side of table, about eight per side. Maine accents, barn in background. Passing cake from one end of table to the other before cutting. As cake passes, those claiming one attribute (moistness) versus the other (lightness), hand off cake to those speaking. Background music at start of ad fades to discussion...

"Well, this cake better be moist..." (Fred, only individual identified by name. Leader of moist faction.)

"You tell them, Fred." (Woman next to Fred, presumably his significant other. Also moist faction.)

"Oh, come on. It's supposed to be light..." (Man immediately opposite Fred. Leader of light faction.)

"That's right!" (Woman next to lead of light faction. From this point on the viewer is led to assume that those on the left are proponents of 'moist,' while those on the right favor 'light' texture.)

voice-over: "Some like it moist, some like it light. Now there's something new that's just right -- Duncan Heinz." (Quick-cut to D-H logo).

"That's not new." (Woman originally favoring moistness argues with voice-over.)

voice-over: "It is, too. New improved Light Deluxe is the first yellow cake mix that's both moist and light. Moister and lighter than every other yellow cake mix." (Quick-cut to a shot of a piece of cake. Camera zooms out, and picture is front of D-H box. As attributes mentioned, first 'MOIST' and the 'LIGHT' appear, and rise to position above box.)

voice-over: $\quad$ "See how much higher it rises...!" (Quick-cut to 3 cake pans, side-by-side-by-side. Unidentified brands on left and right; D-H in center. First shown uncooked, quick-cut to following baking. D-H taller than others.)

voice-over: $\quad$ "And as for the taste..."

"Mmm, mmm..." (Individuals on both sides of the picnic bench, simultaneously.)

"It's very moist!" (Man from previous 'light' faction. Hadn't spoken before.)

"But Fred, it's also light...!" (Fred's significant other. Previous 'moist' faction.)

"I know." (Fred: previous 'moist'-faction leader.)

"I heard that." (Male leader of original 'light' faction.)

"We told you, Fred." (Woman from 'light' side of table.)

voice-over: $\quad$ "New Duncan-Heinz Deluxe: the first cake mix to bring moistness to light..."

"This moistness has seen the light... Ha, ha, ha!" (Fred.)

"Ha, ha, ha." (Feigned disgust with Fred's humor by man directly across the table who was the original leader of the 'light' side.)

"Ha, ha..." (Fading echoes by those on either side of table.) 
Camera zooms back showing unified family, all enjoying cake.

Note: In the single-source version a woman argues with herself about wanting a cake that is moist, but also light. She talks to herself (and the camera) before serving the cake to her family. Near the end she makes the same "This moistness has finally seen the light" joke, which her family apparently overhears. They join her "Ha, ha, ha" line, and are seen enjoying the cake together.

Notes 